THE CHALLENGES OF GLOBALIZATION:

\title{
THE STRATEGIC ROLE OF LOCAL MANAGERS IN JAPANESE-OWNED U.S. SUBSIDIARIES
}

\author{
by \\ VLADIMIR PUCIK \\ CORNELL UNIVERSITY
}

November 1992

Working Paper \# 93-03

This paper has not undergone formal review or approval of the faculty of the ILR School. It is intended to make results of Center research, conferences, and projects available to others interested in human resource management in preliminary form to encourage discussion and suggestions. 
THE FEAR OF SUCCESS

After spending billions of dollars moving manufacturing plants to all corners of the world, and endowing numerous programs in Japanology in the world's best institutions of learning, Japanese companies have just uncovered a disconcerting truth: their competitors do not love them. Winning in global competition and being popular are clearly two different things. Reacting to this sudden realization, some well-known Japanese industrialists, and in particular the SONY chairman Akio Morita, called for a reexamination of the competitive strategies of Japanese firms. Morita argued that if the Japanese changed the way they compete in the global markets by putting less emphasis on growth and more emphasis on profits, not only they would be able to win the respect and affection of their competitors, but Japanese employees and shareholders would be better off too (Morita, 1992). The notion of "harmonization" (kyosei) seems to replace "internationalization" (kokusai-ka) as the new guiding light of corporate Japan.

In his specific recommendations, Mr. Morita called for the reduction of working hours while raising both salaries and dividends, all of this funded from increased profit margins. These could be secured if the current market-share driven business strategies were to be discarded in favor of strategies focused on product profitability. This should allow Japanese firms to pay higher salaries to their employees as well as give more attention and yens to community and environmental needs.

Propery of 
All these goals are commendable from the viewpoint of key corporate stakeholders, but the world's consumers would have to be willing to bear the costs in terms of higher prices for Japanese products. In a free market economy, this is unlikely to happen. In fact, fatter profits may come only through a further increase in the competitiveness of Japanese firms, thus leading to even sharper conflicts with firms in the host countries.

However, the merit of Morita's proposals is not an issue here, as the starting point of the debate should be the diagnosis of the underlying problem, not just a review of the proposed solutions. In this sense, the premise of this chapter is the opposite to that of Morita; the strategic challenge to Japanese multinationals overseas is not that they are "too competitive" vis-a-vis their local rivals, their problem is that they are not competitive enough.

In my view, the profit handicap of many Japanese multinationals is not caused by a misplaced management strategy emphasizing market share growth over profits, as argued by Morita and others. Rather, the low levels of profits may reflect the failure to globalize the corporate management to the degree that it has the capacity and ability to capture the appropriate returns from global operations. For too many Japanese firms the slogan "think globally, act locally" is not a statement of corporate strategy, but a reflection of the current division of labor: the Japanese do the thinking, while the acting is left to the locals. 
The resistance to increasing Japanese presence overseas is driven by similar shortcomings of corporate management, namely the failure to integrate the local management into the global framework, thus providing the "transplants" with at least some degree of immunity against resentment and rejection as, for example, the U.S. firms were able to do in Europe since the era of "The American Challenge". Nor surprisingly, the resistance to the Japanese is again strongest in Europe, and it was upon return from Europe that Morita wrote his now famous essay.

However, both sets of factors that put the Japanese global firms on the defensive have little to do with their drive to compete. Reducing the intensity of competition may therefore not be the appropriate response. To the contrary, the reality of the free-market mechanism is that Japanese multinationals, like firms in every other open economy, would find it difficult to survive without a sharp focus on competition. The vision of a "kinder, gentler" Toyota, Matsushita or Fanuc is in the long run unrealistic.

Past economic history shows clearly that running away from competition undermines healthy corporate culture, breeds complacency, and encourages short-term thinking. The absolute pursuit of cushier margins may perhaps lead to the same kind of competitive decline that many Western firms have been experiencing in the last two decades. I doubt, however, that such a competitive decline would make Japanese multinationals any more liked, although certainly they would be less feared. 


\section{FAILED GLOBALIZATION}

From a broader perspective, Morita's pronouncements can, therefore, be viewed as an implicit admission that Japanese companies failed to globalize their competitive spirit. By and large, they were not able to build up strong management teams of local executives, who would internalize the concept of global competition. Not only this saps the vitality of the overseas subsidiaries, but the lack of capability to compete globally will inevitably damage the parent company as well.

The recent deterioration of the competitive position of many Japanese global firms in the North American market put this issue in a sharp relief. According to the MITI 1991 survey of Japanese companies with operations overseas and data released by the U.S. Department of Commerce, Japanese manufacturers experienced a sharp decline in profitability in both their manufacturing and sales operations. The Us $\$ 1.5$ billion surplus of local plants and sales operations in 1988 turned into a loss of US $\$ 1.3$ billion by 1991, with even larger losses expected in 1992 (Yamada, 1992).

While the overall business results may be influenced by external factors such as the recession in the U.S., data for individual firms show similar deteriorating tendencies. Typical examples are the $\$ 500 \mathrm{mil}$. loss incurred in 1991 by Bridgestone in their so-far unsuccessful takeover of Firestone, the $\$ 100+\mathrm{mil}$ write-off by Kubota of a failed high-tech venture capital investment, and the well-known difficulties of sony and 
Matsushita and their Japanese competitors in the consumer electronics business (Thorton, 1992) .

Some observers see examples of failed globalization especially in the area of sales and marketing management (e.g. De Nero, 1990). It is being argued that the marketing strategies of Japanese firms often do not sufficiently take into account market differentiation. The poor fine-tuning of products limits the value-added created in local operations. Slow and unresponsive decision making in this area is seen as a common weakness of Japanese global firms due to their heavy centralization and dominance of head-office functional organizations (in most cases, manufacturing or sales).

slow and centralized decision making is also blamed for a very spotty record in Japanese acquisitions overseas. Attractive deals have to be closed quickly, yet prudent analysis of business conditions inside the target firm is also essential. As Japanese firms are often not able to do this in a timely manner, they developed a reputation not only for paying too much for their acquisitions, but also for accumulating problems rather than assets. This applies not only to the "go-go" Japanese real estate companies rushing to the U.S. during the cheap-yen era of the late 1980s, but also to such conservative Japanese firms such as Matsushita (acquisition of MCA) and Bridgestone (acquisition of Firestone).

It is being asserted repeatedly that these examples of failed globalization are due to the well-known propensity of 
Japanese firms to rely mainly on their own home-grown managers in directing their overseas investment activities. For example, according to surveys of MITI, worldwide only less than 50 percent of executive positions are filled by local nationals (MITI, 1991). In service firms, the ratio is even lower - less than 30 pcrcent are occupied by locals. In contrast, according to the preliminary data compiled by Japan's Labor Ministry for Western multinationals operating in Japan, over 80 percent of such positions are filled by Japanese.

However, the challenge of an effective implementation of global competitive strategies goes much beyond the power, the numbers and the country of origin of the expatriate executives. As many U.S. multinational firms have discovered to their dismay, merely replacing expatriates with locals does not solve the fundamental problem facing firms in a global environment: how to reconcile the seemingly conflicting demands of national responsiveness and global integration (Bartlett and Ghoshal, 1988; Kobrin, 1992).

The challenge of globalization is not in managing the tradeoffs among these divergent needs, but in incorporating the conflicting strategic objectives into a new type of globallycompetitive organization (Pucik, 1992). Can Japanese firms manage this process? What role should be played by local executives in Japanese overseas affiliates that would optimize their contribution to the competitive strategies of the subsidiaries as well that of their parent firms? 
THE FOCUS OF INQUIRY

This paper reviews three core issues that reflect the globalization challenge confronting Japanese multinational companies today. They all relate to the decision making roles and responsibilities of locally recruited managers and executives. However, in contrast to most of the traditional writing on Japanese-owned operations overseas, the emphasis of the discussion is not on the "fairness" or "good citizenship" of the Japanese firms in terms of their employment practices, but on the linkage of decision-making systems and management practices with company performance.

Such an approach is necessary because, in my view, the clear failure to increase the influence of local executives during the past decade is at least partly due to the fact that empowering local managers was seen by many Japanese firms only as a show of good will, rather than a necessity of business. Yet, it may not possible to challenge this attitude without a better understanding of how organizational practices facing local executives and managers working for the Japanese, as well as their behavior and attitudes, impact the key performance indicators.

The first issue to consider is the most general: to what extent does the globalization of decision making (i.e. making business decisions on the basis of a tightly coordinated global strategy) influence firm performance, such as profitability or market share. Also, what is the impact of global integration on 
the job satisfaction and morale of local managers? These questions are also addressed more specifically by examining the correlation between global integration in specific business functions (such as manufacturing or finance) and key performance variables.

The second set of issues focuses on the degree of inyolvement by local managers and executives in corporate decision making and its linkage with the performance of the firm. This study examines the relationship between managerial involvement in various parts of the decision-making process and the key performance variables, and also analyzes managerial preferences for changes in the decision-making mechanism in terms of a more effective globalization.

Finally, the third core area concerns the perceived benefits of genuine globalization. These are highlighted by comparing the current and optimal decision-making patterns in terms of the location of decision-making authority and the nationality of participants, and by Iinking these comparisons with indicators of subsidiary performance. Again, the two sets of decision-making patterns are analyzed, disaggregated by specific functional areas.

The three critical groups of issues facing Japanese multinationals, as they deal with the demands of globalization, are reviewed in the context of a larger study that analyzed the management culture and effectiveness of local managers and executives in major Japanese affiliates in the United States 
(Pucik, Hanada \& Fifield, 1989). The data for this research came from an extensive survey of top-level American managers in 32 major Japanese-owned affiliates supplemented by in-depth interviews with local executives and senior Japanese expatriates. The firms in the sample were mainly large and "established" Japanese multinationals. Two-thirds of the firms studied were engaged in manufacturing, the rest were in finance and other services. Most of the firms were among the largest in their Iines of business in Japan, including a number of market leaders, and also had extensive overseas business experience, the average presence in the United States being 18 years. However, several firms had already accumulated more than 30 years of U.S. business experience.

132 questionnaires were distributed by mail to U.S. executives who were at the time of the survey assigned to one of the top three management layers in the local affiliate. 82 questionnaires were returned for a response rate of $61 \%$, which is relatively high for this kind of research. The complete demographic profile of the sample was described fully elsewhere (Pucik, Hanada \& Fifield, 1989). In addition, 51 executives were interviewed in person.

In addition, in order to understand better the perspective of the parent firms, a number of interviews were then conducted throughout 1990 and 1991 in the head office of the firms that participated in the survey. In a series of in-depth interviews, home-office executives in charge of "globalization strategy" were 
interviewed in the form of a dialogue about the interpretation of results from the original survey.

\section{THE INFLUENCE OF GLOBALIZATION}

As proposed by Bartlett and Ghoshal (1988), the trend toward a "transnational corporation" that balances global efficiency, multinational responsiveness and worldwide learning, is the dominant organizational reaction to the forces of globalization. However, it was also proposed that Japanese firms may face a particulary difficult challenge managing the transition from a "global" efficiency mode of operations to a multi-focal "transnational mode" (Bartlett \& Yoshihara, 1989), because of their fundamental weakness in integrating local managers into the global organization.

To shed light on this issue, the degree of integration of specific business functions with the parent company in Japan was examined first, measuring to what extent a company was being managed on a global basis. Predictably, the responses varied by industry, company, and function, but in general, the local senior managers reported a moderate but increasing level of business integration and globalization across the board. Their observations were confirmed during interviews with $\mathrm{HQ}$ staff in Japan.

Business planning and fund procurement were two functions that were most consistently managed from a global perspective. These results parallel an earlier research conducted by MITI (1991) that reported similar conclusions. Among manufacturing 
firms, a heavy emphasis was also placed on global coordination of the parts and components networks, in particular in the field of consumer electronics, where U.S. based operations are highly dependent on the linkage to manufacturing facilities in south East Asia.

on the other hand, firms in the automobile industry expressed inteyest in a regional, rather than global approach to purchasing coordination, capitalizing on the increasing presence of their affiliated suppliers in North America. In most cases, however, the so-called North American HQ was still a semi-empty corporate shell, lacking power and resources to influence the decision making. Several U.S. executives reporting to such a "regional center" expressed the frustration of being continuously outflanked by their Japanese "subordinates" informally linked to their "mother plants" in Japan.

Personnel management, management training, distribution, and marketing were globalized the least. The weak global linkage of management training is particularly striking, given the key role assigned to management development in the process of global integration (Evans, 1992). This makes it difficult to implement two key objectives of global human resource strategies: development of a common corporate culture as the "glue" binding the network of subsidiaries, and career planning for highpotential managers from the local operations. Without a global direction and coordination, any such programs are generally too scattered, unfocused and short-lived. 
The weakness of the global "cultural" glue came out clearly in our interviews with local American executives. Their knowledge of HQ strategies, policies, and culture was often minimal, even to the point that many of them could not agree about such basic business facts as thejr parent firms's sales volume and number of employees. While poor information flow from Japan was clearly an issue (most routine communications from the HQ still comes by fax in Japanese), the lack of concern for the "big picture" on the part of some of the U.S. managers was indeed striking.

Utilizing the data on globalization of specific business functions, an aggregate "globalization index" was computed. To no surprise, subsidiaries involved in manufacturing were more integrated on a global basis than affiliates engaged only in distribution or finance. This reflected the well-known reliance of Japanese overseas subsidiaries on the Japanese parent and its manufacturing network for product design and critical components (EPA, 1991). No major differences with respect to overall integration were observed within the manufacturing sector, as differerces in coordination strategies among individual firms seem at this point larger than differences among sectors.

According to the data, the older manufacturing subsidiaries were more closely integrated with the parent firm than newer affiliates. Thus the "late-globalization" hypothesis, namely that local affiliates will become more "naturalized" over time (e.g. Kreinin, 1989), just as happened with most U.S. subsidiaries in Europe, is not supported. This probably reflects the fact that 
Japanese manufacturing firms who entered into the U.S. early are those that can benefit most from global integration and coordination.

)

In fact, some of youngest Japanese-owned operations reported most autonomy. These were mainly firms recently acquired (however, the sample size is too small to lend itself to a statistical test). Until the onset of the "bubble crisis", Japanese firms were mainly content to let their new acquisitions run as before, often even without integrating them to their existing U.S. operations. However, because of resource scarcity at home, and some significant management failures in the U.S., such a "hands-off" strategy is now being reconsidered.

The competitive advantage gained from business globalization is clearly reflected in the survey data, as we observed a significant relationship between the degree of globalization and the overall performance of the subsidiary (Figure 1). A high degree of business globalization is also strongly correlated with the achievement of specific performance objectives, in particular market share and speed of new product development. There was no significant relationship between levels of profitability in the subsidiary and the degree of globalization. It may be, however, that because of transfer pricing and other financial maneuvers, the true level of profitability is impossible to estimate.

FIGURE 1 ABOUT HERE 
For specific business functions, the strongest positive impact on overall performance comes from the globalization of the product planning, product development, research, and parts procurement areas. Other functions have shown no significant relationship to the level of performance. An expected negative relationship between the global integration of marketing strategies and subsidiary performance was also not observed.

At the same time, while globalization has in general a positive impact on performance, it is also associated with lower employee morale, and diminished satisfaction with job autonomy and managerial role. In particular, the globalization of marketing and personnel policies seems to have the most pronounced negative effect. While these factors may not be directly linked to poor business performance, they may in fact contribute to conflicts between Japanese and U.S. managers often reported in the business press.

In other words, the results can be best described as a "globalization paradox". High óverall integration of business activities is strongly correlated with the achievement of most performance objectives, in particular with market share, new product development and conformance with budget. On the other hand, high globalization is negatively associated with most measures of job satisfaction, such as satisfaction with job autonomy or scope of the managerial role.

The survey data illustrate an additional point that may impact the job satisfaction of local managers and executives: the 
degree of formal autonomy granted to the subsidiaries does not parallel a decrease in the presence of Japanese expatriates. To the contrary, global business integration and expatriate presence are negatively correlated. The weight of Japanese nationals among the top management team was consistently larger in subsidiaries where local managers reported weaker global integration. only in the personnel area dia the expatriate presence contribute to a tighter linkage with global policies and systems.

A large Japanese staff may indicate a corporate emphasis on "cultural" control (Pucik \& Katz, 1986) allowing for more decentralization and less formal coordination between the headquarter in Japan and the U.S. subsidiary, than in more "traditional" Japanese firms. In other words, the overseas operations can be integrated into the global network either through formal reporting and planning systems, or through informal channels of communications controlled by Japanese expatriates.

The dilemma facing many U.S. executives working for the Japanese is that they don't like the formal "global" reporting system that, in their opinion, stifles the decision-making autonomy of the local operations, but find it equally hard to accept the extensive Japanese presence in an "autonomous" subsidiary. However, from the Japanese HQ point, the policy choice is not so much focused on the role of local executives, merely on what kind of "ethnocentric" control would be the most appropriate. Without "local" managers with a "global" mind, 
alternative control systems, such as empowering local managers to represent corporate interests, are not feasible.

\section{INVOLVEMENT IN DECISION MAKING}

The generally negative impact of global integration on job satisfaction and morale among local executives can be analyzed further by examining the degree of involvement of American executives and managers in making critical business decisions in contrast to the involvement of executives in the Japanese HQ or Japanese staff dispatched to the U.S. Fifteen such decision areas were identified ranging from the formulation of the subsidiary's middle-range plans and the development of new products to decisions concerning sales promotion methods and the compensation of local executives.

Ten different decision-making alternatives (organizational levels differentiated by national origin and location of decision-makers) were specified on the survey form: from decisions made solely by senior executives in Japan to those delegated entirely to local managers in the subsidiary. Joint decision-making patterns were also an option. Based on the responses, the ten levels were then combined into six decisionmaking modes (Figure 2).

According to the survey participants, primary responsibility for most business decisions today still rest with Japanese. Out of all decision-making points examined, 47 percent involved only Japanese staff, including 22 percent where the decision-making responsibility was located exclusively in Japan. In contrast, 
American executives maintained exclusive decision-making prerogatives only in 18 percent of the cases. When the U.S. managers were involved in HQ decision making, it was mostly together with their Japanese colleagues resident in the U.S. Even then, local executives were not involved in more than 53 percent of all decisions.

\section{FIGURE 2 ABOUT HERE}

The functional areas where the local executives were most heavily involved are primarily in the marketing domain, e.g. product pricing, sales and profit targets, and sales promotion. This again partly contradicts observations made by DeNero (1989) who attributed the low profitability of many Japanese-owned U.S. operations to insufficient input of local marketing executives into the decision-making process. The survey data indicate that the cause of poor performance may not be the lack of local decision-making authority in the marketing area, but a weak linkage of short-term operational decisions with the strategic direction of the firm.

Interviews confirmed the observations from the survey. Most American executives asserted that strategic planning activities were performed mainly in Japan. The U.S. side supplied schedules, forms, and numbers, but was not integrated into the planning process at the head office. Only a few of the local executives that were interviewed had any clear understanding of what the 
corporate long-term plans and strategies were. Many appeared to have a limited time horizon defined by the length of the current budget cycle in the subsidiary.

Comments from a banking executive - "I don't know if there is a five-year program for building a long-term position. They probably have such a plan in Tokyo, but I have not seen it." reflect a general feeling expressed by many other U.S. managers. Clearly, the long-term focus, presented so often as one of the core values of Japanese management culture, does not assert itself in the overseas subsidiaries - at least not from the local perspective. The lack of input into the strategic planning process was therefore a common source of frustration for local management.

Predictably, local executives and managers are least involved in decisions concerning core research programs in Japan, and the establishment of new subsidiaries, factories, and branches. However, the specific decision-making pattern varied not only by firm and function, but often within a firm. Paradoxes were frequent. In a securities firm, only very broad limits were set by Tokyo on risk exposure -- a key strategic indicator in this business -- but even routine space decisions needed to be cleared by the headquarter.

The actual strategic planning mechanism varies by firm, although in general a typical medium-term plan would be less specific in comparison with business plans most American executives were used to in their previous jobs. While some may 
view this as an advantage and an opportunity to take the initiative, the lack of specificity was often disturbing: "Not really being on the inside and not knowing the real direction of the bank, we surrendered planning to Japan," acknowledged another high-level American banker.

To complicate matters, the involvement of local executives in strategic planning was determined as much by the "credibility" of individuals as by their formal position in the organizational hierarchy. Credibility with the Japanese was not, however, gained from a well-designed strategy of career development, or from long-term appraisals of managerial performance, which most Japanese firms in the U.S. still lack. It was usually deeply personalized and dependent on a relatively unpredictable combination of "soft" managerial traits and behaviors, and on the sponsorship by influential Japanese.

In the survey, local executives were also asked to indicate where, based on their personal judgement, the individual business decisions should be made (Figure 2 above). Not surprisingly, they would like to see more decisions delegated to the local management. However, because of the highly competitive environment, they also do not see a far-reaching decentralization as very desirable at this point in time. Joint decision making by transnational teams involving executives and staff at the Japanese parent firm, Japanese expatriates, and the local management staff was by far the preferred pattern of decision making. 
It should be pointed out that such a "global" perspective is fairly unique among most local managers of multinational firms. For example, data collected in Japan show that local managers working for Western multinationals strongly believe that a unilateral decentralization of decision-making authority would be most desirable. The $\mathrm{HQ}$ influence is seen mainly as a negative factor in local performance (Pucik, 1991). In contrast, most U.S. managers working for the Japanese see global coordination as essential for maintaining the competitive advantage. They just would like to take a greater part in this process.

The key question remains, however, whether the desired increased decision-making involvement of local executives would have a positive impact on the performance of Japanese subsidiaries. While absolute proof of such a "what if" scenario is, of course, not feasible, it may be possible to estimate the direction of the impact of increased shared decision making by analyzing the existing relationship between local management participation in the decision-making process with the subsidiary performance.

This can be done by computing correlations between several key performance measures (level of profits, market share, employee morale, and overall performance relative to the industry), as reported by local managers, and the degree of their involvement in the decision making relevant to the specific business areas and functions. The key observations are presented in Figure 3 . 
The data suggest an across-the-board positive contribution derived from a localization of the decision-making authority to most performance measures. As can be expected, among all performance indicators, employee morale is most affected by the degree of involvement in key decision-making areas. However, what is most relevant to concerns expressed by Akio Morita, the profitability measure is strongly associated with an increased input from local executives on issues related to business planning and development of products for the U.S. market. Market share performance was positively influenced by the involvement of local managers in a plan formulation, product design and development, and in decisions about promotions and compensation of local executives. The latter indicates substantial opportunities to improve the alignment of the reward and recognition systems with corporate business objectives. Again, local participation in the marketing domain (sales pricing, margins, and sales promotions) did not come out as significant.

The involvement of local executives and managers in corporate strategy planning and new product development is consistently among the strongest indicators of subsidiary performance. In fact, these two variables are the only two impacting the overall performance level. From this perspective, 
the business logic supporting local participation in strategy formulation seems to be overwhelming.

\section{GLOBALIZATION GAP AND CORPORATE PERFORMANCE}

The latent benefits of increased participation by local executives in corporate strategy determination can be further illustrated by comparing the current and perceived optimal decision-making patterns, and then correlating these comparisons with indicators of subsidiary performance. In order to do that, a "globalization gap" index was computed from the two sets of responses regarding the location of decision-making responsibility, as the difference between where the key decisions are made today, and where they should be optimally made, according to the survey respondents. The correlation of the "gap index"" with principal performance measures is presented in Figure 4 .

\section{FIGURE 4 ABOUT HERE}

In the majority of decision-making areas, as well as in the aggregate, the size of the "globalization" gap was negatively correlated with most performance measures. Subsidiaries where local executives perceived a smaller globalization gap performed significantly better. In seven out of the eight key decisionmaking areas, the globalization gap had a negative impact on market share, in six out of seven key areas, it had a negative impact on the level of profits and overall performance. Not 
surprisingly, employee morale was adversely affected by the globalization gap in all decision-making areas.

Product development including design changes, and the reward and recognition systems (promotions and compensation), were the two decision-making areas where the globalization gap had the most consistently negative influence on subsidiary performance. Two of the marketing decision areas, product pricing and margin determination, were also shown as being sensitive to the size of the globalization gap. This may perhaps explain some of the observations listed by DeNero (1990).

While these results further reinforce the earlier findings about the relationship between the involvement of local managers in decision making and corporate performance, some caution in interpreting them is in order. It cannot be ruled out that the responses to the survey may contain a certain bias, as it is likely that the globalization gap is probably most apparent in low-performing firms. Poor business results are often a priori attributed by local executives to a lack of their influence and input into the decision-making process -- in this data set, employee morale and globalization gap in plan formulation exhibit the highest correlation.

on the other hand, however, interviews with local executives again and again highlighted the general unhappiness of most American executives with their exclusion from the strategy formulation process. This was often attributed to the Japanese unwillingness to share strategic information because of their 
(often legitimate) fears that local managers may leave the firm and take the knowledge with them. Thus a vicious circle is created: local managers leave because they object to being excluded from the inner core, which then serves as a justification for the exclusion of their successors.

The formal reporting structure of many U.S. affiliates further complicates the picture. Although many local manufacturing operations are nominally autonomous from product divisions in Japan, this is not always the case in reality. The "behind the scenes" influence was quite frustrating to many U.S. executives who felt locked out of the critical stages of the planning and decision-making processes. The frustration was often exacerbated by perceptions that many of the Japanese expatriates involved in these negotiations are primarily representatives of a particular factory or division who do not put much value in protecting the interest of the American subsidiary, and sometimes even of the global firm as a whole.

In this respect, many executives both in the U.S. and in Japan pointed out the critical "bridging" role of Japanese expatriates. Their willingness and ability to share with local managers information on developments in the head office was an important factor influencing the perception of local executives about their role in the firm. Influential local executives do not resent their Japanese "shadows", but actively seek out the very best they can get to work with them. "To be successful here," commented one such local senior executive, "you need an effective 
'shadow', someone who can deliver for you, someone who has the respect of the Japanese organization."

It has often been said that the dominance of Japanese staff in the decision-making process is caused by the relative "youth" of Japanese multinationals in contrast with their more matured Western counterparts. However, neither the survey data, nor the interviews, provide much support tor this hypothesis. To the contrary, in many firms, the frequency of top-down decision making dominated by the Japanese was reported to have increased, rather than decreased, over time. A changing role of the Japanese expatriate staff was often the issue.

An American executive remarked in a candid interview: "In the past three years, there has been a major change in the approach to the Japanese market by Japanese firms in my business. Previously, American management was in the forefront and was strongly involved in establishing goals, strategy, and tactics. The Japanese operated as controllers, auditors, and communicators between the Japanese HQ and the U.S. subsidiary. Today, Japanese managers -- the new breed -- believe that they are smarter than Americans and can be in "line" positions."

According to observations made by the HQ staff in Japan, the shift in the mode of control was mainly due to the increased strategic value of the local investment. The term "globalization" to this Japanese firm as well as to many other firms with a similar philosophy of overseas expansion, means mainly an ability to manage globally with a core Japanese management staff. When 
globalization implies getting by without the locals, it is no surprise that there is no love lost.

\section{IMPLICATIONS FOR THE FUTURE}

The data from the survey and the interviews show that market share continues to be an important strategic objective of Japanese subsidiaries. At least in manufacturing, market share in conjunction with continuous cost reduction programs is expected to translate into increased margins and profits. High margins without the benefit of market share protection are seen as vulnerable to attacks from determined competitors. This business logic served Japanese firms well in the past, and the current rhetoric on "kyosei" notwithstanding, it is doubtful that they can shift gears in the near future.

However, as pointed out earlier, the pressures for higher profits are real and are not likely to diminish in future. It is doubtful that Japanese overseas subsidiaries, and in particular those in the U.S., can cope with the harsh environment without making sure that their local managers and executives become true partners in the global decision making. As shown repeatedly in the analysis presented here, this is not a matter of "good citizenship". Empowering local management is, first of all, "good business", essential for success in a global competition.

In addition, without opportunities for meaningful local input into corporate-level decision making, Japanese firms will not even be able to retain for long the management talent they desperately need. No one is immune from competition for capable 
people, as was recently demonstrated by the defection of the top local executives at Honda, a company aspiring to become the first true Japanese "transnational".

However, more is involved in restoring profitability to overseas subsidiaries than just avoiding local executive turnover. Many American managers working for the Japanese see strategies to increase profitability as a futile effort, as subsidiary profits are regularly transferred to Japan. This is not so much an issue of tax avoidance (although at present the U.S. tax authorities are reviewing closely the tax returns of most major Japanese firms). It is more a matter of accepted corporate policy that profits are to be channeled to the home office or home division, often with the blessing of the local tax code. This does not make much difference to the fortunes of the expatriate Japanese, but it has a considerable demotivating effect on the local managerial staff.

In this situation, it is only natural that local executives, when left with a choice, prefer to invest in building the market, rather than to concentrate on making the market profitable, or else they simply stop being concerned with profitability at all. When plans come from above, and it is virtually impossible to attain high profitability for local operation, why try at all? Thus, any serious attempt to increase profitability on a global basis must first deal with restructuring the "who and where" in terms of decisions on strategic objectives, to be able to draw on resources and capabilities worldwide. 
In order to support integrated decision making, the reward and recognition system for local managers and executives will have to be aligned with global objectives. Paradoxically, for Japanese firms to move in this direction, they need first to become more "Japanese". They need to learn to manage their Iocal staff with the same care and determination that they show at home. This must start already at the entry level, with more efforts dedicated to attract qualified management candidates. In order to do so, Japanese companies need to offer careers, not just jobs -- just like they do in Japan.

Because at least some experience in the parent firm is essential for a succesful career with most Japanese companies (just like in any multinational firm), the availability of meaningful career opportunities for local executives at the head office in Japan is the benchmark of a company's commitment to true globalization. To prepare managers to take advantage of these opportunities then requires a substantial increase in investment for training and development. Only then is the full integration of local managers into the global network possible.

There is no doubt that the severity of global competition will force many Japanese multinationals to rethink their policies with respect to local management, in particular in the developed economies of the U.S. and Europe. They have no choice, if they want to survive. However, this will not happen automatically as companies mature, but only through committed effort, continuous experimentation, and trial and error. 
The strength of excellent global companies is in their ability to capitalize on internal diversity. It is this diversity that promotes the flexibility and innovation needed to compete globally. Developing people who can manage effectively in a heterogeneous environment is not easy, and to maintain a steady course toward real globalization will be the ultimate test of corporate Ieadership. This is what the top Japanese industrialists should be concerned about. 


\section{REFERENCES}

Bartlett, C.A. and S. Ghoshal, (1988). Managing Across Borders. Cambridge, MA.: Harvard Business School Press.

Bartlett, C.A. and H. Yoshihara, (1988). "New Challenges for Japanese Multinationals." Human Resource Management. 27, $1: 19-43$

DeNero, H. (1990). "Creating the "Hyphenated" Corporation." The Mckinsey Quarterly. $4: 153-174$.

EPA (Economic Planning Agency), (1991). Keizai Hakusho (White Paper on the Japanese Economy). Tokyo, Japan: Okura-sho. Evans, P. (1992) . "Management Development as Glue Technology."

Human Resource Planning. 15, 1:85-106.

Kobrin, S.J.'(1992). "Multinational strategy and International

Human Resource Management Policy." Working Paper. The

Wharton School. University of Pennsylvania.

Kreinin, M.P. (1989). "How Closed is Japan's Market? Additional

Evidence." The World Economy, 11:4:42-52.

MITI (Ministry of International Trade and Industry). 1991. Kaigai

Jigyo Katsudo Doko Chosa no Gaiyo (The Survey on Activities

of Japanese Overseas Subsidiaries), Tokyo, Japan: Okura-sho. Morita, A. (1992). "Nihon-gata Keiei ga Abunai (Crisis of

Japanese Corporate management)." Bungei Shunju. 2:

Pucik, V. (1991) . "Japanese Managers, Foreign Bosses." Journal of Japanese Trade \& Industry. 1: 43-45.

Pucik, V. (1992). "Globalization and Human Resource Management." In V. Pucik, N.M. Tichy \& Carole K. Barnett. Globalizing 
Management. New York: John Wiley \& Sons. 61-81.

Pucik, V., M. Hanada and G. Fifield, (1989). Management culture and the Effectiveness of Local Executives in Japanese-owned U.S. Corporations. Ann Arbor, MI: The University of Michigan.

Pucik, V. and J. H. Katz. (1986). "Information, Control and Human Resource Management in Multinational Firms". Human Resource Management. 25, 1: 121-132.

Thorton, E. (1992). "How Japan Got Burned in the U.S.A." Fortune. June 15: 114-116.

Yamada, M. (1992). "Survive, Relocate or Withdraw." Tokyo Business Today. $60,6: 18-21$. 
Figure 1

INTEGRATION, PERFORMANCE, AND SATISFACTION

Correlation coefficients

$\square$ Not significant relationship

Significant relationship $(p<.05)$

Very significant relationship $(p<.01)$

RELATIONSHIP WITH FUNCTIONAL INTEGRATION

\begin{tabular}{lll}
\hline & EXECUTIVE & EXPATRIATE \\
OVERALL PERFORMANCE & SATISFACTION & PRESENCE
\end{tabular}

\begin{tabular}{|c|c|c|c|c|c|}
\hline Negative & Positive & Negative & Positive & Negative & Positive \\
\hline Business planning & 18.18 .16 & 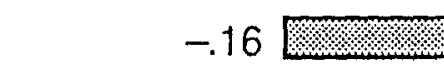 & & $- . 1 8 \longdiv { 6 }$ & \\
\hline Research & (1) & $-.06 \square$ & & -.02[ & \\
\hline Product development & 1.27 & & $\square .04$ & $-.21 \%$ & \\
\hline Marketing & $\begin{array}{l}16 \\
\end{array}$ & -.331 & & & $\square .11$ \\
\hline Procurement & \%.24 & 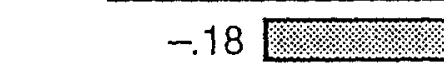 & & -.25 & \\
\hline Operations & $\square .12$ & $-.12 \square$ & & $- . 2 1 \longdiv { \square }$ & \\
\hline Distribution & $\square .11$ & -.10 & -.38 & & \\
\hline Personnel & $\square .05$ & $-.27 \mid$ & & . & 7.23 .23 \\
\hline Training & $\square .14$ & & 1.01 & -.07 & \\
\hline Accounting & 0.02 & -.10[ & & -.07 & \\
\hline Legal affairs & J.01 & -.10[ & & $-.14 \square$ & \\
\hline Funding & $\square .05$ & $-.10 \square$ & & $-27 \square$ & \\
\hline Overall integration & צ. & $- . 2 2 \longdiv { . 1 . 8 . 8 . 1 . 8 }$ & & $- . 2 2 \longdiv { 8 }$ & \\
\hline
\end{tabular}


Figure 2

\section{DECISION LOCATION MATRIX}

Percent

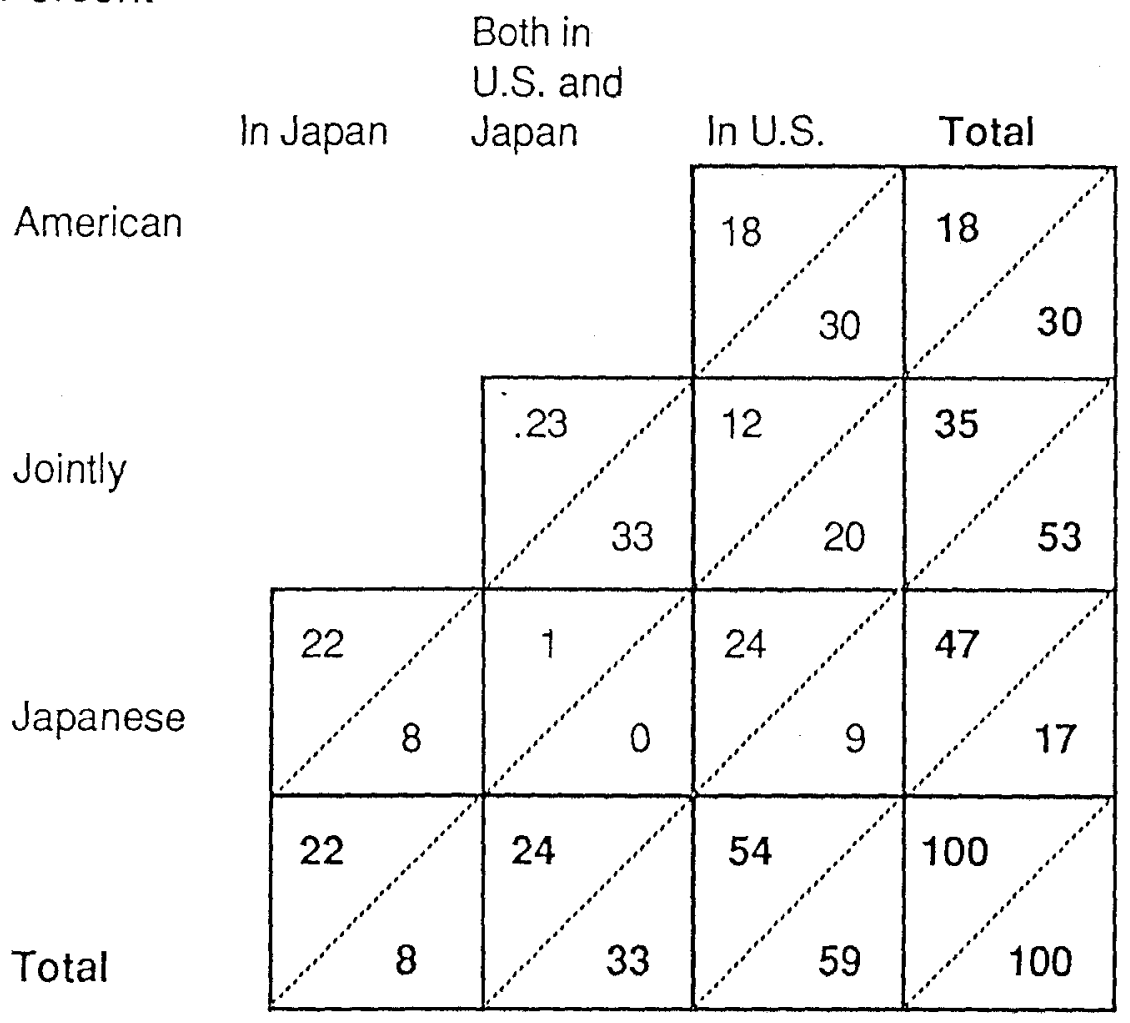

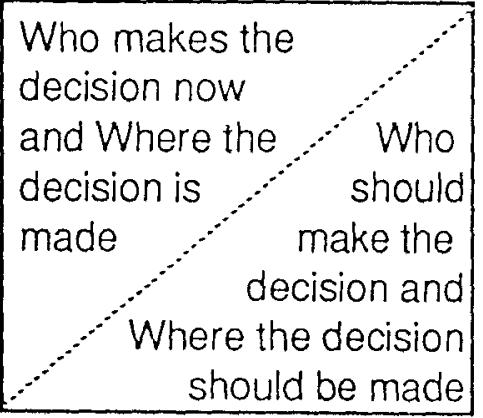


Figure 3

\section{INVOLVEMENT IN DECISION-MAKING}

\section{AND PERFORMANCE}

Correlation coefficients betweën performance measures and degree of involvement of local managers in decision-making

Not significant contribution

Significant contribution $(p<.05)$

Very significant contribution $(p<.01)$

\begin{tabular}{|c|c|c|c|c|}
\hline \multirow[b]{2}{*}{ Decision areas } & \multicolumn{2}{|c|}{ Performance indicators } & \multirow[b]{2}{*}{$\begin{array}{l}\text { Employee } \\
\text { morale }\end{array}$} & \multirow[b]{2}{*}{$\begin{array}{l}\text { Overall } \\
\text { performance }\end{array}$} \\
\hline & $\begin{array}{l}\text { Level of } \\
\text { profits }\end{array}$ & $\begin{array}{l}\text { Market } \\
\text { share }\end{array}$ & & \\
\hline Plan formulation & 20 & .39 & .32 & 31 \\
\hline New product development & 26 & 17 & 26. & 18. \\
\hline Changes in design & : 2 & 19 & .15 & .14 \\
\hline Pricing & .13 & .15 & 19 & .10 \\
\hline Sales promotions & .03 & -.01 & 23 & .03 \\
\hline Profit margins & .12 & .14 & 20 & .10 \\
\hline Executive promotions & .07 & & .21 & .11 \\
\hline Compensation & .12 & & .06 & .08 \\
\hline Overall involvement & .11 & & $17 \%$ & .11 \\
\hline
\end{tabular}


Figure 4

INVOLVEMENT IN DECISION-MAKING AND PERFORMANCE: IMPACT OF LOCALIZATION GAP ON PERFORMANCE

Correlation coefficients

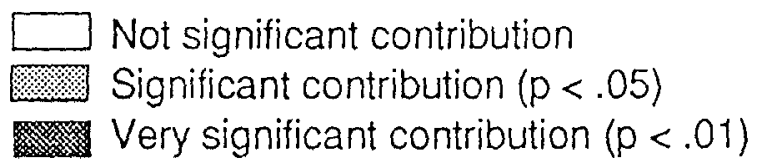

\begin{tabular}{|c|c|c|c|c|}
\hline \multirow[b]{2}{*}{ Decision areas } & \multicolumn{4}{|c|}{ Performance indicators } \\
\hline & $\begin{array}{l}\text { Level of } \\
\text { profits }\end{array}$ & $\begin{array}{l}\text { Market } \\
\text { share }\end{array}$ & $\begin{array}{l}\text { Employee } \\
\text { morale }\end{array}$ & $\begin{array}{l}\text { Overall } \\
\text { performance }\end{array}$ \\
\hline Plan formulation & -.14 & 2.23 & $x-.41$ & 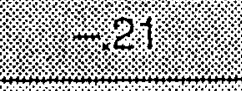 \\
\hline New product development & . & 2.2. & & 125 \\
\hline Changes in design & & $1.9 \%$ & & 2.26. \\
\hline Pricing & (2) & (1) & & 2 \\
\hline Sales promotions & -.07 & -.02 & (2.-2. & -.05 \\
\hline Profit margins & .01 & 19 & 20 & -.09 \\
\hline Executive promotions & 1.9 & (2) 26 & -.3 & 2.26 \\
\hline Compensation & -.36 & -.30 & -.37 & -.36 \\
\hline Overall involvement & 3.24 & (:) & -.34 & 2.24 \\
\hline
\end{tabular}

